\title{
Extraction and preconcentration of parabens in liquid pharmaceutical samples by Dispersive Liquid-Liquid Microextraction based on deep eutectic solvent
}

SAMANEH sahebian ( $\nabla$ s.sahebian@um.ac.ir)

Ferdowsi University of Mashhad https://orcid.org/0000-0001-5378-6615

\section{N. Razavi}

Ferdowsi University of Mashhad, Mashhad, Iran

\section{F. Foroutan}

Ferdowsi University of Mashhad, Mashhad, Iran

\section{J.Vahdati Khaki}

Ferdowsi University of Mashhad, Mashhad, Iran

\section{Research Article}

Keywords: Paraben, deep eutectic solvent, dispersive liquid liquid microextraction, pharmaceutical samples, high-performance liquid chromatography

Posted Date: February 11th, 2022

DOI: https://doi.org/10.21203/rs.3.rs-1337548/v1

License: @ (i) This work is licensed under a Creative Commons Attribution 4.0 International License. Read Full License 


\section{Abstract}

In this paper dispersive liquid-liquid microextraction using deep eutectic solvent, as one of extraction solvent was considered for preconcentration and determination of parabens in liquid pharmaceutical samples. Deep eutectic solvent (DES) composed of choline chloride $(\mathrm{ChCl})$ hydrogen bond acceptor) and hydrogen bond donor (glucose) was provided the highest extraction efficiency. Thermogravimetry analysis (TGA), X-ray diffraction and Fourier-transform infrared spectroscopy (FT-IR) were selected to prove that the synthesis of DES was done successfully. The Liquid chromatography with photodiode array detection (HPLCDAD) was used for analysis of paraben species. Parameters affecting the extraction efficiency were studied and optimized through univariate analysis and experimental design. Under the optimal conditions ( $\mathrm{pH}$ of aqueous solution: 4.5, ethanol as the disperser solvent, glucose DES as the extraction solvent) the linearity range of $0.1-5000 \mathrm{ng} \mathrm{mL}^{-1}$ was obtained with the coefficient of determination $\left(R^{2}\right)$ ranging in 0.993-0.9962. Limits of detection (LOD) ranged from $0.04-0.15 \mathrm{ng} \mathrm{mL}^{-1}$ with the relative standard deviations from 1.78-6.85\%. The developed method was applied to determination of parabens in liquid pharmaceuticals such as ampule, syrups and nose drop samples. The relative recoveries in these real samples were in the range of $80.95-103.12 \%$.

\section{Introduction}

Like other products, such as food, detergents, cosmetics, and sanitary products, pharmaceuticals especially those based on water need preservatives to prevent microbial contamination [1]. Parabens are one of the most commonly used preservatives in these compounds [2]. Parabens are esters of $p$-hydroxybenzoic acid. The most common parabens are methylparaben, ethylparaben, propylparaben, butylparaben. By adding parabens will help to extend product's shelf life and protect us from germs [3]. These preservative compounds (parabens) with low toxicity, good stability, non-volatility and non-irritability properties are efficient for such applications [4]. However, we cannot ignore the destructive effects of these materials. Parabens could change endogenous hormone action or synthesis, they may also affect the reproductive system or nervous system [5]. Parabens specious have high octanol water coefficients which lead to dissolve them in fatty tissues (bioaccumulate) [6] and they have been proven to be one of the cause of breast cancer. As, the use of certain types of parabens has been prohibited [7]

In order to find out the amount of parabens in different samples, the preconcentration and extraction of analytes usually performed before instrumental analysis.

Liquid phase extraction and solid phase extraction techniques are two main categories of extraction methods that are carried out in variety of ways. For example, liquid phase microextraction (LPME) [8], single-drop microextraction (SDME) [9], hollow-fiber liquid-phase microextraction (HF-LPME) [10] and dispersive liquid-liquid microextraction (DLLME) are modified forms of liquid phase extraction technique. They offer higher enrichment factor and/or extraction efficiency and lower organic solvent consumption rather than classic techniques $[11,12]$. Among these techniques, dispersive liquid-liquid microextraction has significant attention by providing high enrichment factor which is dispersion of extraction solvent throughout the sample solution $[13,14]$.

Deep eutectic solvents were recently introduced to solvents, they are referred to as green solvents. They are mixture of Lewis or bronsted acids and bases. In these solvents one or more compound mixed and produced a eutectic solvent with a melting point significantly lower than either of the individual components, they are mostly liquid at room temperature. The components should combine in particular molar ratio to observe this state $[15,16]$.

Deep eutectic solvents provide valuable benefits such as easy preparation with high purity, environmental compatible, safe, cheap, and low toxicity $[17,18]$.

In DLLME for extraction of analytes, the extracting solvent which is microliters of a water-immiscible high density organic solvent in the form of a cloudy solution (fine droplets) dispersed throughout the aqueous phase by means of dispersive solvent (miscible in both extracting and aqueous phases) $[19,20]$. Since the extraction solvent dispersed in all part of the sample solution, this technique has the great extraction efficiency. The use of deep eutectic solvents as extraction solvent in DLLME technique will also help improve the enrichment factor. Choosing the DES in this technique depend on some physical features 
like viscosity, density, solubility, freezing point and polarity [21, 22]. Usually, the DES with higher density than water will be used overall, these solvents are extensively used as an extraction solvent in dispersive liquid liquid microextraction for extraction of various analytes.

In the present study we develop application of DES based glucose for DLLME extraction of parabens in liquid pharmaceutical samples.

\section{Experimental}

\subsection{Materials}

The analytical purity methyl paraben (MP) (logP 1.91, pKa 8.87), ethyl paraben (EP) (logP 2.34, pKa 8.90), propyl paraben (PP) (logP 2.94, pKa 8.87), butylparaben (BP) (logP 3.50, pKa 8.79) were obtained from Sigma-Aldrich (St. Louis, USA).

The HPLC-grade methanol and acetonitrile, ethanol, acetone, hydrochloric acid (37\%), dichloromethane, and ethylene glycol were obtained from Merck (Darmstadt, Germany).

glucose, choline chloride, phenol, menthol, glycerol, sodium hydroxide and sodium chloride all of these reagents and other chemicals were of analytical grade. Doubly distilled water was used for preparation of aqueous solution prepared in the lab using a Water Purification System (HUMAN POWER 1, Korea).

Pharmaceutical samples such as nasal drop, syrup and ampoule were purchased from neighborhood pharmacies.

\subsection{Preparation of standard solutions}

The mixed stock solution of MP, EP, PP, BP was prepared in methanol at a concentration of $1000 \mu \mathrm{gmL}^{-1}$ and stored at $4{ }^{0} \mathrm{C}$. Also, the standard working solutions were daily prepared by dilution of stock standard solution with distilled water to the required concentrations. The $\mathrm{pH}$ of aqueous solutions was adjusted by hydrochloric acid or sodium hydroxide. After finding optimized conditions, different samples prepared in acetic acid- sodium acetate buffer.

\subsection{Instrumentation}

Separation and determination of parabens were performed by HPLC-DAD. The HPLC system consisted of Agilent 1260 (Santa Clara, CA 95051. United States), Agilent 1260 Infinity Bio-inert Quaternary Pump, Agilent 1260 Infinity Bio-inert Manual Injector valve equipped with a $20 \mu \mathrm{L}$ sample loop, a vacuum degasser, and a column compartment, coupled to a DAD, A Zorbax Eclipse XDB C18 column, $150 \mathrm{~mm} \times 4.6 \mathrm{~mm}, 5 \mu \mathrm{m}$, at an oven temperature of $25^{\circ} \mathrm{C}$ was used for separation, Agilent 1260 Infinity Diode Array Detectors (DAD) and Agilent ChemStation software. The degassed mobile phase was a mixture of methanol-pure HPLC grade water $(60: 40 \%, v / v)$ and the flow rate was $1 \mathrm{~mL} \mathrm{~min}{ }^{-1}$. The analytes were detected by DAD at wavelength, $254 \mathrm{~nm}$. Centrifugation of solutions were carried out by Iranian Behdad Digital centrifuge. FT-IR spectroscopy analysis was applied to analyze the presence of molecular interactions between choline chloride and glucose. This investigation was performed by Thermo-Nicolet AVATAR 370 FT-IRw/SMART Endurance ATR (Canada) in the range of $400-4000 \mathrm{~cm}^{-1}$ in spectral-grade $\mathrm{KBr}$ pellets. Aliquots of $1.0 \mathrm{~mL}$ liquid sample (DES) was scanned in the wavelength range of $4000-400 \mathrm{~cm}^{-1}$. In order to investigate the thermal stability of DES, glucose and choline chloride a TGA-50, shimadzu was used from RT up to $823 \mathrm{~K}$ at heating rates of $10 \mathrm{~K} / \mathrm{min}$.

\subsection{Preparation of real samples before extraction}

0.5 milliliter of each liquid pharmaceutical samples was diluted to $10 \mathrm{~mL}$ by distilled water and then centrifuged. $1.0 \mathrm{~mL}$ of diluted sample was taken to perform extraction.

\subsection{Dispersive liquid-liquid microextraction procedure}

A $5.0 \mathrm{~mL}$ of aqueous buffering solution of parabens was placed in a $10.0 \mathrm{~mL}$ screw cap glass test tube with conic bottom. $798.0 \mu \mathrm{L}$ of ethanol (as a disperser solvent) and the $136.0 \mu \mathrm{L}$ of glucose DES (as the extraction solvent) were mixed and injected 
rapidly into the aqueous sample. The mixture was shaken. A cloudy solution (water/disperser solvent/extraction solvents) was formed in the test tube. In this step, the parabens in water sample were extracted into the fine droplets of extraction solvents. The mixture was then centrifuged for $5 \mathrm{~min}$ at $6000 \mathrm{rpm}$ to accelerate phase separation. Finally, after decanting the upper phase, $10 \mu \mathrm{L}$ of the sedimented phase was injected directly into the HPLC system for further analysis.

The DES peak should have no interferences with analyte peaks in the HPLC chromatogram (during separation).

\section{Results And Discussion}

\subsection{Optimization of extraction conditions}

Kind of solvents were considered and optimized in univarient way. Then, during one step, the other factors influencing the DLLME optimized simultaneously by applying experimental design.

\subsubsection{Selection kind of DES}

The extraction solvents in liquid extraction must have high affinity toward analytes in sample, appropriate chromatographic behavior, easy dispersion in aqueous phase and then separation from it in order to analyzing by instrument $[23,24]$. Thus, choosing the most suitable extraction solvent is of primary importance for achieving good selectivity of the target compounds.

At first, several kind of DES solvents were synthesized and extraction procedure was carried out by help of them. The composition and preparation procedure of different kinds of DES were described in Table 1.

Table 1

Different DES composition

\begin{tabular}{|c|c|c|c|}
\hline $\begin{array}{l}\text { DES } \\
\text { Name }\end{array}$ & DES constitute & $\begin{array}{l}\text { Salt/HBD } \\
\text { ( } \mathrm{mol} / \mathrm{mol})\end{array}$ & DES syntheses \\
\hline $\mathrm{MC}$ & Menthol: $\mathrm{ChCl}$ & $2: 1$ & $\begin{array}{l}\text { Heating mixture at } 85^{\circ} \mathrm{C} \text { with constant stirring until a } \\
\text { homogeneous liquid formed }\end{array}$ \\
\hline PC & Phenol: $\mathrm{ChCl}$ & $2: 1$ & $\begin{array}{l}\text { Heating mixture at } 85^{\circ} \mathrm{C} \text { with constant stirring until a } \\
\text { homogeneous liquid formed }\end{array}$ \\
\hline GCW & Glucose: ChCl: Water & $1: 2: 2$ & $\begin{array}{l}\text { Heating mixture at } 85^{\circ} \mathrm{C} \text { with constant stirring until a } \\
\text { homogeneous liquid formed }\end{array}$ \\
\hline GLYC & Glycerol: $\mathrm{ChCl}$ & $2: 1$ & $\begin{array}{l}\text { Heating mixture at } 85^{\circ} \mathrm{C} \text { with constant stirring until a } \\
\text { homogeneous liquid formed }\end{array}$ \\
\hline EGC & Ethylene glycol: ChCl & $4: 1$ & $\begin{array}{l}\text { Heating mixture at } 85^{\circ} \mathrm{C} \text { with constant stirring until a } \\
\text { homogeneous liquid formed }\end{array}$ \\
\hline MEGCFe & $\begin{array}{l}\text { Ethylene glycol: } \mathrm{ChCl} \text { : } \\
\mathrm{FeCl}_{3}\end{array}$ & $4: 1: 1$ & $\begin{array}{l}\text { Heating the mixture at } 80^{\circ} \mathrm{C} \text { until a clear and homogeneous liquid } \\
\text { formed }\end{array}$ \\
\hline MD & $\begin{array}{l}\text { DL menthol } \\
\text { :Dodecanoic acid }\end{array}$ & $2: 1$ & $\begin{array}{l}\text { Heating mixture at } 85^{\circ} \mathrm{C} \text { with constant stirring until a } \\
\text { homogeneous liquid formed }\end{array}$ \\
\hline MA & $\begin{array}{l}\text { DL menthol :Acetic } \\
\text { acid }\end{array}$ & $1: 1$ & $\begin{array}{l}\text { Heating mixture at } 85^{\circ} \mathrm{C} \text { with constant stirring until a } \\
\text { homogeneous liquid formed }\end{array}$ \\
\hline
\end{tabular}

The preparation process for all of these DES is almost the same and easy. They were usually synthesized by heating different hydrogen bond donor (HBDs) and ammonium salt (eg. $\mathrm{ChCl}$ ) to $80 \sim 85^{\circ} \mathrm{C}$ along with constant stirring until the emergence clear liquid. To keep the temperature constant, the process was performed in an oil bath. 
To consider the performance of each DES on extraction efficiency, $5.0 \mathrm{~mL}$ aqueous sample of parabens (1 ppm) was selected, 1 $\mathrm{mL}$ methanol as dispersing solvent plus the $200 \mu \mathrm{L}$ of each kind of DES as the extraction solvents were injected into the aqueous solution after shaking, the sample solution was centrifuged for $5 \mathrm{~min}$ at $6000 \mathrm{rpm}, 10 \mu \mathrm{L}$ of the sedimented phase used for quantification analysis by HPLC.

Extraction efficiency (peak area) was evaluated based on the type of DES and shown in Fig. 1.

Magnetic DES also can be seen in this consideration, by entering $\mathrm{FeCl}_{3}$ in $\mathrm{DES}$ constitute, the

$\mathrm{FeCl}^{-}{ }_{4}$ anion formed and the solvent gets magnetic, however, extraction with this solvent was not very efficient rather than others.

Based on this diagram, the highest extraction efficiency (peak area) was obtained by using DES of glucose (GCW) as an extraction solvent. In general, density values of DES are higher than water which is favor of DLLME technique by reducing the requirement time for separation of the phases [19].

Carbon tetrachloride (usual dispersive extraction solvent) was used without DES to extract paraben species, which did not have a satisfactory result.

\subsubsection{Characterization of glucose DES}

The FT-IR spectra of pure compounds as well as DES of glucose were obtained and analyzed.

Figure 2 depicted the IR spectrum of $\mathrm{ChCl}$, the strong and almost broad peak in $3235 \mathrm{~cm}^{-1}$ related to stretching vibration of hydroxyl group $(\mathrm{OH})$, this $\mathrm{OH}$ group can form inter and intramolecular hydrogen bond, bands at $1085 \mathrm{~cm}^{-1}$ and $1012 \mathrm{~cm}^{-1}$ are appeared for $\mathrm{C}-\mathrm{N}$ stretching vibration, $1482 \mathrm{~cm}^{-1}$ refer to the presence of an alkyl groups. On the other hand, 3200 to $3400 \mathrm{~cm}^{-1}$ band assigned to $\mathrm{OH}$ groups (vibrational stretching) in glucose, $1026 \mathrm{~cm}^{-1}, \mathrm{C}-\mathrm{O}$ stretching vibration, $1376 \mathrm{~cm}^{-1} \mathrm{C}-\mathrm{OH}$ vibration, $772 \mathrm{~cm}^{-1}, \mathrm{C}-\mathrm{H}$ out-of-plane bending.

When glucose and choline chloride are hydrogen bonded together to form liquid deep eutectic, DES, FTIR spectrum pattern changed, the most important changes seen in hydroxyl band that participated in the formation of the hydrogen bond, as can be seen this peak gets wider, Fig. 3.

Band of vibration $\mathrm{C}-\mathrm{H}$ group shift to $1479 \mathrm{~cm}^{-1}$ with change in intensity, on the other hand, the $\mathrm{C}-\mathrm{O}$ stretching vibrations also appears in $1080 \mathrm{~cm}^{-1}$ [25-28].

Figure 4 presents the variation of weight percentage and derivative of the weight percentage (TGA-DTG) curves of glucose, choline chloride and DES samples in the temperature range from room temperature to $823 \mathrm{~K}$. According to figure $4 \mathrm{a}$ and $4 \mathrm{~b}$, the thermal degradation of choline chloride consists of two distinct stages: first step related to water loss which was proved by $\mathrm{OH}$ band of FT.IR spectra pattern. The main thermal degradation step occurs in temperature range $562-618.8 \mathrm{~K}$, leaving only $4.6 \% \mathrm{wt}$ solid residue.

As seen Fig. 4, a rapid weight loss (5.79\%wt) in the temperature interval of 337-357.5 K as moisture content of glucose. Glucose begins to decompose at around $456 \mathrm{~K}$ and with mass loss of $99.8 \% \mathrm{wt}$ at $803 \mathrm{~K}$. Besides, figure 4 presents the onset thermal degradation of DES is lower than glucose and choline chloride. Based on FTIR spectrum pattern of DES, there is more mass loss in temperature range $303-433 \mathrm{~K}(13.6 \% \mathrm{wt})$ as moisture content compared to glucose and choline chloride (Fig. 4). DES begins to decompose at around $448 \mathrm{~K}$. Besides, there is $22.5 \% \mathrm{wt}$ residue mass at $803 \mathrm{~K}$.

Figure (5) shows the XRD pattern of the DES (GCW) and mixture of glucose and choline chloride. As it can be seen, the peaks are related to the crystal phases of glucose (JCPDS no.00-001-0374) and choline chloride (JDPDS no. 00-033-1581). Besides, the synthesized DES has amorphous structure as no significant sharp peak and completely peaks of glucose and choline chloride disappear. 


\subsubsection{Selection the disperser solvent}

Disperser solvent is applied in DLLME to enhance the dispersion of extraction solvent throughout the aqueous phase by decreasing the interfacial tension. Therefore, this solvent must be able miscible in both the aqueous phase and the organic phase $[29,30]$. By employing the disperser solvent, extraction efficiency will be improved. For this purpose, four usual disperser solvents, methanol, ethanol, acetonitrile, acetone, were examined. Extractions were performed by using $5.0 \mathrm{~mL}$ aqueous solution, $200 \mu \mathrm{L}$ of DES (glucose) as the extraction solvent, $1.0 \mathrm{~mL}$ of different each of disperser solvent

Figure 6 depicts the most peak areas were obtained when the ethanol was the disperser solvent. Ethanol was chosen the disperser solvent in subsequent experiments. By means of ethanol as a disperser, acceptable repeatability obtained while the peak areas were lower than other solvents. Ethanol is the main parabens solvent that can dissolve them and of course completely miscible with water, therefore, the extraction efficiency will be improved [31].

With the use of acetonitrile as a disperser solvent, cloudy mode was sometimes not formed. That was the reason for reduced repeatability.

\subsubsection{Optimization of dispersive liquid liquid microextraction conditions using central composite design}

After selecting the extraction and disperser solvents individually, the other four important factors affecting the dispersive liquidliquid extraction ( $\mathrm{pH}$ of the aqueous sample, salt addition and volume of DES and ethanol) were simultaneously investigated and optimized in one step.

Optimization procedure was carried out by employing the response surface method (RSM) with a central composite design (CCD) technique. This design contains four main parameters, by applying the CCD method including 31 experiments (runs) with 7 Center points the relation between parameters and their response were obtained.

The low and high levels of these factors in two-level factorial (Full fraction) design were as follow: $\mathrm{pH}$ of sample solution (3-9), salt \% (0-10\%), volume of DES (50-150 $\mu \mathrm{L})$ and volume of dispersion solvent (300-1000 $\mu \mathrm{L})$. By establishing one block (1 day) 31 experiments were carried out. The peak area of each paraben species was considered as the response of each experiment.

To minimize the effect of uncontrolled factors on the response, all tests were done randomly. Table 1s. summarizes the design of experiments as uncoded and real values and shows the response value for extraction of each analyte. Practical response obtained in each experiment (Table 1s) was used to calculate the response descriptor model for each of the factors and the equation was obtained and applied (Table. 2s).

\subsubsection{Analysis of variance (ANOVA)}

The result and equations of the model was statistically analyzed by ANOVA method (Table 3s). The ANOVA method predicts one-way effects, interactions, and the second-order factors on the response.

The probability value defined as $p$ value, the parameters having $p$ value lower than 0.05 in the ANOVA indicated to be significant effect on the response at a confidence level of $95 \%$.

On the other hand the F-value is the ratio of mean square for the individual term to the mean square for the residual.

In order to test the null hypothesis, F value and $\mathrm{P}$ value are compared. In this way, the statistical significance of effects can be estimated. The results of ANOVA method for the methyl paraben was considered as an example in Table 3s. According to the Table 3s, it can be found that all the variables had a significant effect on the response and had a $p \leq 0.05$. In this model, F-value is great that implies the model is significant [32,33].

The evaluation the significance of the model was performed by the lack-of-fit test, Lack of Fit (LOF) is a symbol of the variation of data around the obtained model used for criterion judging the suitability of a model for fitting experimental data. If the LOF of 
the model was significant indicates that model would be inappropriate for embedding empirical data, the resulting $\mathrm{p}$ value for the LOF is 0.915 (Table 3s) indicates the ability of the model to describe the experimental data and the obtained optimum points. The $\mathrm{R}^{2}$ coefficient consideration will also help to confirm the result, $\mathrm{R}^{2}$ coefficients compare experimental data and predict values by the model. For PP, R-sq was obtained $94.77 \%$ that means the data were fitted well and only $5.23 \%$ of the total variance was not explained by the model. Furthermore, the adjusted R-squared is a modified version of $R^{2}$ for the number of predictors in a model, while an R-squared value between 0 and 100 and shows the linear relationship in the sample of data even when there is no basic relationship, the adjusted R-squared gives the best estimate of the degree of relationship in the basic population. Methyl paraben had the adjusted $R^{2}$ value (R-sq(adj) (90.19\%) that reveals the satisfactory correlation between the experimental data and the obtained model.

Finally, the experimental data were analyzed by constructing a polynomial equation, in fact, the mathematical equation between the detector response for each analyte and each of the factor. Desirability function (DF) condition also was applied to get the optimum conditions where the maximum peak area find out for each factor. DF values are between 0 to 1 , indicating a minimum and maximum value of optimum conditions, respectively [34, 35].

In this research, Minitab 17 software was applied for prediction the optimum values for each of the studied parameters, obtaining the DF value and finding the desirable conditions profile.

The optimum conditions where the peak areas (responses) of each analyte meet its maximum value should be found. Peak areas are the symbol of the efficiency of the method. The graphs of maximizing the desirable conditions to attain optimum conditions could be seen in Fig. 1s.

According to Fig. $1 \mathrm{~s}$, it is clear that the best efficiency was obtained by setting the $\mathrm{pH}$ of aqueous solution 4.45 , the amount of salt $5 \%$ and the volumes of glucose and ethanol $127.0 \mu \mathrm{L}$ and $774.0 \mu \mathrm{L}$ respectively.

Parabens are parahydroxybenzoic acid, they are hydrolyzed in acidic environment, in ionized formed disperse better in ethanol and then it is better absorb to extraction solvents, followed by preconcentration and extraction. This trend is similar to previous researches [36, 37].

DES of glucose has the hydroxyl groups (from glucose and choline chloride) that can participate in the formation of hydrogen bond, carboxy groups of parabens and hydroxyl groups of DES form hydrogen bond. Therefore medium acidic $\mathrm{pH}$ would be favor to this phenomena [38].

As the $\mathrm{pH}$ further increased, the peak areas decreased dramatically. Parabens are in ionic forms at $\mathrm{pH}$ higher than the pKa values of the analytes. It is difficult to absorb into the organic solvents. Therefore, pH adjustments were performed by using buffer of acetate at 4.5 .

The influence of ionic strength of aqueous solution on the performance of extraction was investigated. It is performed by addition different amount of $\mathrm{NaCl}(0-10 \%)$. Increasing the salt up to $5 \%$ causes a significant increase in the extraction efficiency, however, further addition of $\mathrm{NaCl}$ due to the high viscosity of the solution and difficulty diffusion of analyte towards extraction solvent leads to a decrease in the yield.

As the amount of glucose was increased to $150.0 \mu \mathrm{L}$, the responses were also rise at the same time for all of the analytes. 774 $\mu \mathrm{L}$ ethanol as the disperser solvent would be sufficient for dispersing throughout the solution and helping the extraction and preconcentration of analytes.

\subsection{Analytical performance}

The method was evaluated under optimum condition, the linear range, limit of detections (LODs), limit of quantifications (LOQs), repeatability, enrichment factor (EF), and extraction recovery (ER) were obtained for this purpose. At first, several parabens solutions with known concentration in buffer solution were prepared, the DLLME were performed on them, then the analytical figures were calculated through these solutions. 
Detection limit is defined as three times signal to noise, in other word, the minimum concentration of analyte that produces the chromatogram peak area equal to 3 times the peak area of the noise[39]. LOQ or limit of quantification is also calculated in same way only the signal-to-noise ratio will be $10[39,40]$. Table 1

The reproducibility of the extraction procedure over one day and the repeatability of the method between three days at three levels of concentration (low, medium, high) were considered. The standard solutions of parabens prepared after performing the extraction procedure on them, the relative standard deviation between responses calculated and introduce as the precision of the method [41]. Table 2 shows these results.

The comparison between the results of extraction parabens from the standard samples with the known concentration and real sample under optimal conditions lead to find the recovery of the method and also matrix effect. The relative standard deviation (RSDs) was calculated to check the accuracy of the method.

The calibration curves were constructed using 10 concentration levels. By linear regression of the peak area versus standard concentrations of parabens.

The standard mixtures of 4 parabens in a concentration range of $0.01-5000 \mathrm{ng} \mathrm{mL}^{-1}$ were prepared for calibration curves, then linear regression of peak area against standard concentrations plotted individually for each analyte. The extraction procedure repeated 3 times for each concentration level.

Preconcentration factor expressed the ratio between the paraben concentration after extraction in sedimented phase to initial concentration $[42,43]$.

Eqs. (1)(2) were used for calculation of enrichment factor and recovery, respectively.

$$
E F=C_{s e d} / C_{a}
$$

1

$$
E R \%=\frac{C_{\text {sed }} \cdot V_{\text {sed }}}{C_{a} \cdot V_{a}} \times 100=\left(\frac{V_{\text {sed }}}{V_{a}}\right) \times E F \times 100
$$

2

$\mathrm{C}_{\text {sed }}$ was concentration of analyte in sedimented phase, $\mathrm{C}_{\mathrm{aq}}$, concentration of analyte in aqueous phase, $\mathrm{V}_{\text {sed }}$ volume of sedimented phase and $\mathrm{V}_{\mathrm{a}}$ volume of aqueous phase.

Final volume of sedimented phase was $50.0 \mu \mathrm{L}$ and initial aqueous volume was $5.0 \mathrm{~mL}$ 
Table 2

The characteristics of the method

\begin{tabular}{|c|c|c|c|c|c|c|}
\hline Analyte & $\begin{array}{l}\text { Linear range } \\
n g m L^{-1}\end{array}$ & $\begin{array}{l}\text { LOD } \\
n g m L^{-1}\end{array}$ & $\begin{array}{l}\mathrm{LOQ} \\
n g m L^{-1}\end{array}$ & $\mathbf{R}^{2}$ & $\begin{array}{l}\text { EF } \\
\left(C_{\text {sed }} / C_{a q}\right)\end{array}$ & $\begin{array}{l}\mathrm{ER} \% \\
\mathrm{C}_{\mathrm{sed}} / \mathrm{C}_{\mathrm{aq}} \times 100\end{array}$ \\
\hline MP & $0.1-5000$ & 0.03 & 0.1 & 0.9962 & 47.73 & $47.73 \%$ \\
\hline EP & $0.5-5000$ & 0.15 & 0.5 & 0.9955 & 55.39 & $55.39 \%$ \\
\hline PP & $0.1-5000$ & 0.04 & 0.1 & 0.9959 & 67.65 & $67.65 \%$ \\
\hline $\mathrm{BP}$ & $0.1-5000$ & 0.04 & 0.1 & 0.9934 & 75.05 & $75.05 \%$ \\
\hline
\end{tabular}

Table 3

The method precision parameters

\begin{tabular}{|llllll|}
\hline $\begin{array}{l}\text { Precision } \\
\mathrm{n}=5\end{array}$ & $\begin{array}{l}\text { Concentration } \\
\mu g \mathrm{~L}^{-1}\end{array}$ & $\mathrm{MP}$ & $\mathrm{EP}$ & $\mathrm{PP}$ & $\mathrm{BP}$ \\
\cline { 2 - 6 } & $\mathbf{0 . 0 0 1}$ & 4.41 & 3.68 & $\mathbf{6 . 8 5}$ & $\mathbf{5 . 9 5}$ \\
\cline { 2 - 6 } & $\mathbf{0 . 1}$ & $\mathbf{2 . 0 5}$ & $\mathbf{3 . 2 1}$ & $\mathbf{5 . 1 2}$ & $\mathbf{4 . 7 9}$ \\
\hline 1 & $\mathbf{1 . 7 8}$ & $\mathbf{2 . 2 1}$ & $\mathbf{4 . 9 4}$ & $\mathbf{3 . 4 8}$ \\
\hline $\begin{array}{l}\text { Reproducibility } \\
\text { (Three days) }\end{array}$ & 4.57 & 4.31 & 7.08 & 8.25 \\
Conc.0.5 $\mu \mathrm{g} \mathrm{mL}^{-1}$ & & & & \\
\hline
\end{tabular}

\subsection{Real sample analysis}

The results of this study were evaluated by analyzing the parabens in real samples. Liquid pharmaceutical samples were chosen for investigation the capability of the method for extraction of parabens in real samples. Samples were prepared initially according to section 2.4 .

Because the complete compositions (matrix) of these pharmaceuticals were unknown, the standard addition method was used to find the amount of parabens added to these samples.

$2.0 \mathrm{~mL}$ of prepared pharmaceutical samples and different amounts of paraben standard solution at a concentration of $0.3 \mu \mathrm{g}$ $\mathrm{mL}^{-1}$ and $0.5 \mathrm{~g} \mathrm{NaCl}$ were added to $10 \mathrm{~mL}$ volumetric flasks, the solutions were diluted by buffer solution to the mark. $5.0 \mathrm{~mL}$ of each sample was taken to carried out the dispersive liquid liquid microextraction procedure under the optimum conditions on samples.

After extraction of the analytes by DLLME, the extracts were injected into HPLC for separation and determination of analytes. Parabens amounts were determined in different samples by means of the standard addition curves. The results were collected in Table 4.

According to Table 4, in different kind of pharmaceutical samples, paraben have been found. Therefore, these types of preservative are usually added to these pharmaceuticals. Among the parabens, propyl paraben and butyl paraben are more commonly used species. 
Table 4

Parabens amounts in liquid pharmaceutical samples

\begin{tabular}{|c|c|c|c|c|c|c|c|c|}
\hline Sample & $\begin{array}{l}M P \\
\left(\mu \mathrm{gL}^{-1}\right) \\
(\mathrm{n}=3)\end{array}$ & ${ }^{*}$ R.R\% & $\begin{array}{l}E P \\
\left(\mu \mathrm{gL}^{-1}\right) \\
(n=3)\end{array}$ & $\begin{array}{l}\text { R.R } \\
\%\end{array}$ & $\begin{array}{l}P P \\
\left(\mu g \mathrm{~mL}^{-1}\right) \\
(\mathrm{n}=3)\end{array}$ & $\begin{array}{l}\text { R.R } \\
\%\end{array}$ & $\begin{array}{l}\text { BP } \\
\left(\mu \mathrm{g} \mathrm{mL}^{-1}\right) \\
(\mathrm{n}=3)\end{array}$ & $\begin{array}{l}\text { R.R } \\
\%\end{array}$ \\
\hline Nasal drop & ${ }^{* \star} \mathrm{ND}$ & - & ND & - & $340 \pm 2.31$ & 90.23 & $179 \pm 3.23$ & 103.12 \\
\hline Syrup no.1 & $830 \pm 5.12$ & 80.95 & ND & - & $158 \pm 4.19$ & 82.31 & $148 \pm 3.18$ & 93.98 \\
\hline Syrup no.2 & ND & & $240 \pm 2.38$ & 95.44 & ND & - & $209 \pm 2.78$ & 99.45 \\
\hline Syrup no.3 & ND & - & ND & - & $322 \pm 4.70$ & 101.25 & ND & - \\
\hline Ampoule no.1 & ND & - & ND & - & $713 \pm 3.14$ & 99.67 & $232.31 \pm 3.15$ & \\
\hline Ampoule no.2 & ND & - & ND & - & $243 \pm 4.34$ & 83.24 & ND & - \\
\hline
\end{tabular}

The accuracy of method was considered by comparison between the extraction of analytes in distilled water and the extraction of parabens in the real sample matrix. The accuracy of the method was confirmed by calculating the relative recovery. Relative recoveries were determined as the percent ratio of the concentrations found in real sample minus the concentration of analyte in the real sample without adding the standard to the spiked distilled water samples. This research was carried out at different concentration levels in the pharmaceutical samples and the results are presented in Table 4.

The sample chromatogram (syrup sample) shown in Fig. 8a related to the DLLME extraction of pharmaceutical sample without adding standard solution and Fig. $8 \mathrm{~b}$ chromatogram after addition of standard solution.

The response of parabens significantly increased after extraction with the DLLME which demonstrated that the extraction by DES successfully pre-concentrated the parabens.

\subsection{Comparison of the results of this study with similar pervious researches}

Table 5 was provided for comparison the results of the present study with the other extraction methods by emphasizing dispersive liquid liquid extraction of parabens in different samples. Parabens can be found in almost all cosmetic and food samples and in all publications, four common parabens, BP MP, EP, PP, have been investigated. The optimized method exhibited comparable or lower limit of detection than earlier methods. The same trend obtained for linear range. It is quite clear that when there is a change in the conditions of the usual DLLME method such as using low-density organic solvent, solidification of floating organic drops or using DES solvent and so on, more satisfactory results are obtained. The lower LODs in our results can be attributed to the use of DES in extraction procedure, which has created better sensitivity. Extraction of parabens from pharmaceutical samples by DLLME was not considered in the past. 
Table 5

Comparison table

\begin{tabular}{|c|c|c|c|c|c|c|c|}
\hline Analyte & $\begin{array}{l}\text { Analytical } \\
\text { instrument }\end{array}$ & $\begin{array}{l}\text { Extraction } \\
\text { method }\end{array}$ & Real sample & $\begin{array}{l}\text { Detection } \\
\text { limit } \\
(\mu \mathrm{g} \\
\left.\mathrm{mL}^{-1}\right)\end{array}$ & $\begin{array}{l}\text { linearity } \\
\text { range } \\
\left(\mu \mathrm{gL}^{-1}\right)\end{array}$ & $\begin{array}{l}\text { RSD } \\
\text { (\%) }\end{array}$ & Ref. \\
\hline $\begin{array}{l}\text { MP } \\
\text { EP } \\
\text { PP } \\
\text { BP }\end{array}$ & $\begin{array}{l}\text { Gas } \\
\text { chromatography(GC) } \\
\text { Flame ionization } \\
\text { detector (FID) }\end{array}$ & DLLME & lake water & $\begin{array}{l}0.003 \\
\text { for MP } \\
\text { and } \mathrm{EP} ; \\
0.002 \\
\text { for PP } \\
\text { and BP }\end{array}$ & $0.05-1$ & $\begin{array}{l}2.0- \\
10.0 \%\end{array}$ & [44] \\
\hline $\begin{array}{l}\text { MP } \\
\text { EP } \\
\text { PP } \\
\text { BP }\end{array}$ & HPLC-UV & $\begin{array}{l}\text { DLLME } \\
\text { low-density } \\
\text { organic } \\
\text { solvent }\end{array}$ & $\begin{array}{l}\text { Tap water } \\
\text { and } \\
\text { Fruit juice } \\
\text { samples }\end{array}$ & $\begin{array}{l}2.1 \times 10^{-5} \\
-4.6 \times 10^{-5}\end{array}$ & $0.001-0.5$ & $\begin{array}{l}4.1- \\
9.3 \%\end{array}$ & [36] \\
\hline $\begin{array}{l}\text { MP,EP } \\
\text { PP,BP } \\
\text { isopropyl } \\
\text { paraben (iPrP) } \\
\text { isobutyl } \\
\text { paraben (iBuP) } \\
\text { heptyl paraben } \\
\text { (HepP) } \\
\text { octyl paraben } \\
\text { (OctP) }\end{array}$ & HPLC-UV & $\begin{array}{l}\text { DLLME } \\
\text { solidification } \\
\text { of floating } \\
\text { organic } \\
\text { drops }\end{array}$ & $\begin{array}{l}\text { plasma } \\
\text { samples and } \\
\text { urine samples }\end{array}$ & $\begin{array}{l}\text { Plasma, } \\
0.0002- \\
0.0004 \\
\text { Urine, } \\
0.0001- \\
0.0004\end{array}$ & $0.001-1.0$ & $\begin{array}{l}\text { less } \\
\text { than } \\
5.4 \%\end{array}$ & [45] \\
\hline $\begin{array}{l}\text { MP } \\
\text { EP } \\
\text { PP } \\
\text { BP } \\
\text { iBuP } \\
\text { isoamylparaben, }\end{array}$ & GC-FID & DLLME & $\begin{array}{l}\text { Aqueous } \\
\text { cosmetic } \\
\text { products }\end{array}$ & $\begin{array}{l}0.0048- \\
0.025\end{array}$ & $\begin{array}{l}\text { MP, } 0.05-10 \\
\text { and } \\
0.025-5.0 \\
\text { for the other } \\
\text { five } \\
\text { parabens }\end{array}$ & $\begin{array}{l}\text { lower } \\
\text { than } \\
8.2 \%\end{array}$ & [46] \\
\hline $\begin{array}{l}\text { MP } \\
\text { EP } \\
\text { PP } \\
\text { BP }\end{array}$ & HPLC-DAD & $\begin{array}{l}\text { In situ DES- } \\
\text { LLME }\end{array}$ & $\begin{array}{l}\text { Environmental } \\
\text { water samples }\end{array}$ & $\begin{array}{l}0.0006- \\
0.0008\end{array}$ & $0.003-1.0$ & $\begin{array}{l}\text { less } \\
\text { than } \\
7.2 \%\end{array}$ & [47] \\
\hline $\begin{array}{l}\text { MP } \\
\text { EP } \\
\text { PP } \\
\text { BP }\end{array}$ & $\begin{array}{l}\text { capillary } \\
\text { electrophoresis (CE) }\end{array}$ & $\begin{array}{l}\text { DLLME with } \\
\text { back- } \\
\text { extraction }\end{array}$ & $\begin{array}{l}\text { Human milk } \\
\text { and other food } \\
\text { samples } \\
\text { (tomato paste, } \\
\text { pickle, mixed } \\
\text { fruit juice and } \\
\text { ice cream) }\end{array}$ & 0.1 to 0.2 & $4.3-10.7$ & $\begin{array}{l}\text { lower } \\
\text { than } \\
3.5 \%\end{array}$ & [48] \\
\hline
\end{tabular}




\begin{tabular}{|c|c|c|c|c|c|c|c|}
\hline Analyte & $\begin{array}{l}\text { Analytical } \\
\text { instrument }\end{array}$ & $\begin{array}{l}\text { Extraction } \\
\text { method }\end{array}$ & Real sample & $\begin{array}{l}\text { Detection } \\
\text { limit } \\
(\mu \mathrm{g} \\
\left.\mathrm{mL}^{-1}\right)\end{array}$ & $\begin{array}{l}\text { linearity } \\
\text { range } \\
\left(\mu \mathrm{gL}^{-1}\right)\end{array}$ & $\begin{array}{l}\text { RSD } \\
\text { (\%) }\end{array}$ & Ref. \\
\hline MP & \multirow[t]{4}{*}{ HPLC-DAD } & DLLME & \multirow{4}{*}{$\begin{array}{l}\text { Liquid } \\
\text { pharmaceutical } \\
\text { samples }\end{array}$} & \multirow[t]{4}{*}{$\begin{array}{l}0.00003- \\
0.00015\end{array}$} & $E P, 0.0005-5$ & \multirow[t]{4}{*}{$\begin{array}{l}1.78- \\
6.85\end{array}$} & \multirow[t]{4}{*}{$\begin{array}{l}\text { This } \\
\text { study }\end{array}$} \\
\hline EP & & With DES & & & and & & \\
\hline PP & & & & & MP, PP, BP & & \\
\hline $\mathrm{BP}$ & & & & & $0.0001-5.0$ & & \\
\hline
\end{tabular}

\section{Conclusion}

The present study considered the dispersive liquid-liquid microextraction of parabens from liquid pharmaceutical samples. By applying deep eutectic solvent in extraction procedure, the new extraction solvent enters to reaction, which helps to better extract the analytes.

The results of TGA, XRD, and FT-IR instruments indicate that synthesis of DES from glucose and choline chloride was done successfully.

The proposed method provides satisfactory analytical merits, it is compatible with HPLC, it reduces the danger of exposure to toxic solvents used for extraction in conventional extraction procedures and requires short extraction time and low solvent. The method showed the low detection limits and relatively broad linear concentration range.

To the best of our knowledge, this was the first time that the DLLME with DES was applied for the determination of MP, EP, PP and BP in liquid pharmaceutical samples with acceptable relative recoveries.

This paper once again demonstrated the great potential of DLLME in preconcentration and analysis of analytes in a short period of time.

\section{References}

1. M Kashid, R., S. G Singh, and S. Singh, Simultaneous determination of preservatives (methyl paraben and propyl paraben) in sucralfate suspension using high performance liquid chromatography. Journal of Chemistry, 2011. 8(1): p. 340-346.

2. Dodge, L.E., et al., Medications as a source of paraben exposure. Reproductive toxicology, 2015. 52: p. 93-100.

3. Croitoru, M.D., et al., Evaluation Of The Ingestion Of Parabens During The Use Of Dental Care Products By Healthy Human Volunteers. life, 2016. 9(13): p. 14.

4. Castelain, F. and M. Castelain, Parabens: a real hazard or a scare story? European Journal of Dermatology, 2012. 22(6): $p$. 723-727.

5. Błędzka, D., J. Gromadzińska, and W. Wąsowicz, Parabens. From environmental studies to human health. Environment international, 2014. 67: p. 27-42.

6. Darbre, P.D., et al., Concentrations of parabens in human breast tumours. Journal of Applied Toxicology: An International Journal, 2004. 24(1): p. 5-13.

7. Qian, F., Manufacturing method of preservative-free facial mask and process equipment thereof. 2019, Google Patents.

8. Sarafraz-Yazdi, A. and A. Amiri, Liquid-phase microextraction. TrAC Trends in Analytical Chemistry, 2010. 29(1): p. 1-14.

9. Gioti, E.M., et al., Single-drop liquid-phase microextraction for the determination of hypericin, pseudohypericin and hyperforin in biological fluids by high performance liquid chromatography. Journal of Chromatography A, 2005. 1093(1-2): p. 1-10. 
10. Sarafraz-Yazdi, A. and Z. Es' Haghi, Comparison of hollow fiber and single-drop liquid-phase microextraction techniques for HPLC determination of aniline derivatives in water. Chromatographia, 2006. 63(11-12): p. 563-569.

11. Yazdi, A.S., N. Razavi, and S.R. Yazdinejad, Separation and determination of amitriptyline and nortriptyline by dispersive liquid-liquid microextraction combined with gas chromatography flame ionization detection. Talanta, 2008. 75(5): p. 12931299.

12. Pengionan, K.G.P.N., Extraction of methylparaben in cosmetics using dispersive liquid-liquid microextraction based on solidification of floating organic drop coupled with gas chromatography flame ionization detector. Malaysian Journal of Analytical Sciences, 2017. 21(6): p. 1289-1298.

13. Grecco, C.F., et al., Determination of parabens in breast milk samples by dispersive liquid-liquid microextraction (DLLME) and ultra-high-performance liquid chromatography tandem mass spectrometry. Journal of the Brazilian Chemical Society, 2019. 30: p. 48-59.

14. Chen, C.-W., et al., Determination of parabens using two microextraction methods coupled with capillary liquid chromatography-UV detection. Food chemistry, 2018. 241: p. 411-418.

15. Zhang, K., et al., A hydrophobic deep eutectic solvent-based vortex-assisted dispersive liquid-liquid microextraction combined with HPLC for the determination of nitrite in water and biological samples. Journal of separation science, 2019. 42(2): p. 574-581.

16. Aroso, I.M., et al., Dissolution enhancement of active pharmaceutical ingredients by therapeutic deep eutectic systems. European Journal of Pharmaceutics and Biopharmaceutics, 2016. 98: p. 57-66.

17. Lan, D., et al., Deep eutectic solvents as performance additives in biphasic reactions. RSC Advances, 2017. 7(64): p. 4036740370.

18. Faraji, M., Determination of some red dyes in food samples using a hydrophobic deep eutectic solvent-based vortex assisted dispersive liquid-liquid microextraction coupled with high performance liquid chromatography. Journal of Chromatography A, 2019. 1591: p. 15-23.

19. Cunha, S.C. and J.O. Fernandes, Extraction techniques with deep eutectic solvents. TrAC Trends in Analytical Chemistry, 2018. 105: p. 225-239.

20. Ma, S., et al., Dispersive liquid-liquid microextraction coupled with pressure-assisted electrokinetic injection for simultaneous enrichment of seven phenolic compounds in water samples followed by determination using capillary electrophoresis. Journal of separation science, 2019. 42(13): p. 2263-2271.

21. Ma, W., W. Tang, and K.H. Row, Characterization of deep eutectic solvents for dispersive liquid-liquid microextraction for phenolics. Analytical Letters, 2017. 50(14): p. 2177-2188.

22. El-Deen, A.K. and K. Shimizu, A green air assisted-dispersive liquid-liquid microextraction based on solidification of a novel low viscous ternary deep eutectic solvent for the enrichment of endocrine disrupting compounds from water. Journal of Chromatography A, 2020. 1629: p. 461498.

23. Mulia, K., et al., Selected natural deep eutectic solvents for the extraction of a-mangostin from mangosteen (Garcinia mangostana L.) pericarp. Int. J. Technol, 2015. 6(7): p. 1211-1220.

24. Kędzierska-Matysek, M., et al. Application of FTIR spectroscopy for analysis of the quality of honey. in BIO Web of Conferences. 2018. EDP Sciences.

25. Ibrahim, M., et al., Analysis of the structure and vibrational spectra of glucose and fructose. Ecletica quimica, 2006. 31(3): p. $15-21$.

26. Troter, D., et al. Preparation and FTIR characterization of choline chloride-based deep eutectic solvents with thiourea and dimethylurea. in Physical Chemistry 2016 13th International Conference on Fundamental and Applied Aspects of Physical Chemistry. 2016.

27. Ge, D., et al., Air-assisted dispersive liquid-liquid microextraction based on a new hydrophobic deep eutectic solvent for the preconcentration of benzophenone-type UV filters from aqueous samples. Journal of separation science, 2018. 41(7): $p$. 1635-1643.

Page 13/19 
28. Saraji, M. and M.K. Boroujeni, Recent developments in dispersive liquid-liquid microextraction. Analytical and bioanalytical chemistry, 2014. 406(8): p. 2027-2066.

29. Berijani, S., et al., Dispersive liquid-liquid microextraction combined with gas chromatography-flame photometric detection: very simple, rapid and sensitive method for the determination of organophosphorus pesticides in water. Journal of Chromatography A, 2006. 1123(1): p. 1-9.

30. Tabrizi, A.B. and A. Rezazadeh, Development of a dispersive liquid-liquid microextraction technique for the extraction and spectrofluorimetric determination of fluoxetine in pharmaceutical formulations and human urine. Advanced pharmaceutical bulletin, 2012. 2(2): p. 157.

31. Yang, H. and A.C. Rasmuson, Solubility of butyl paraben in methanol, ethanol, propanol, ethyl acetate, acetone, and acetonitrile. Journal of Chemical \& Engineering Data, 2010. 55(11): p. 5091-5093.

32. Sadhukhan, B., N.K. Mondal, and S. Chattoraj, Optimisation using central composite design (CCD) and the desirability function for sorption of methylene blue from aqueous solution onto Lemna major. Karbala International Journal of Modern Science, 2016. 2(3): p. 145-155.

33. Fratoddi, l., et al., Response surface methodology for the optimization of phenolic compounds extraction from extra virgin olive oil with functionalized gold nanoparticles. Microchemical Journal, 2018. 138: p. 430-437.

34. Azharul Islam, M., et al., Statistical optimisation by combination of response surface methodology and desirability function for removal of azo dye from aqueous solution. International Journal of Environmental and Analytical Chemistry, 2010. 90(36): p. 497-509.

35. Trinh, T.K. and L.-S. Kang, Application of response surface method as an experimental design to optimize coagulation tests. Environmental Engineering Research, 2010. 15(2): p. 63-70.

36. Çabuk, H., M. Akyüz, and Ş. Ata, A simple solvent collection technique for a dispersive liquid-liquid microextraction of parabens from aqueous samples using low-density organic solvent. Journal of separation science, 2012. 35(19): p. 26452652.

37. Razavi, N. and Z. Es' haghi, Curcumin loaded magnetic graphene oxide solid-phase extraction for the determination of parabens in toothpaste and mouthwash coupled with high performance liquid chromatography. Microchemical Journal, 2019. 148: p. 616-625.

38. Dai, Y., R. Verpoorte, and Y.H. Choi, Natural deep eutectic solvents providing enhanced stability of natural colorants from safflower (Carthamus tinctorius). Food chemistry, 2014. 159: p. 116-121.

39. Prichodko, A., K. Jonusaite, and V. Vickackaite, Hollow fibre liquid phase microextraction of parabens. Open Chemistry, 2009. 7(3): p. 285-290.

40. Shrivastava, A. and V.B. Gupta, Methods for the determination of limit of detection and limit of quantitation of the analytical methods. Chronicles of young scientists, 2011. 2(1): p. 21.

41. Prichodko, A., et al., Hollow fiber liquid phase microextraction of derivatized parabens. chemija, 2011. 22(3).

42. Lin, J., et al., Determination of free and total phthalates in commercial whole milk products in different packaging materials by gas chromatography-mass spectrometry. Journal of dairy science, 2015. 98(12): p. 8278-8284.

43. $X u, D .$, et al., Determination of 23 phthalic acid esters in food by liquid chromatography tandem mass spectrometry. Journal of Chromatography A, 2014. 1324: p. 49-56.

44. Levchyk, V.M. and M.F. Zui, Gas Chromatographic determination of parabens after derivatization and dispersive microextraction. French-Ukrainian Journal of Chemistry, 2015. 3(2): p. 72-79.

45. Shen, X., et al., Application of dispersive liquid-liquid microextraction for the preconcentration of eight parabens in real samples and their determination by high-performance liquid chromatography. Journal of separation science, 2017. 40(22): p. 4385-4393.

46. Wei, $H$. ., et al., Dispersive liquid-liquid microextraction for simultaneous determination of six parabens in aqueous cosmetics. Chemical Research in Chinese Universities, 2014. 30(3): p. 368-373. 
47. Ge, D., et al., A Deep Eutectic Solvent as an Extraction Solvent to Separate and Preconcentrate Parabens in Water Samples Using in situ Liquid-Liquid Microextraction. Journal of the Brazilian Chemical Society, 2019. 30(6): p. 1203-1210.

48. Alshana, U., N. Ertaş, and N.G. Göğer, Determination of parabens in human milk and other food samples by capillary electrophoresis after dispersive liquid-liquid microextraction with back-extraction. Food chemistry, 2015. 181: p. 1-8.

\section{Figures}

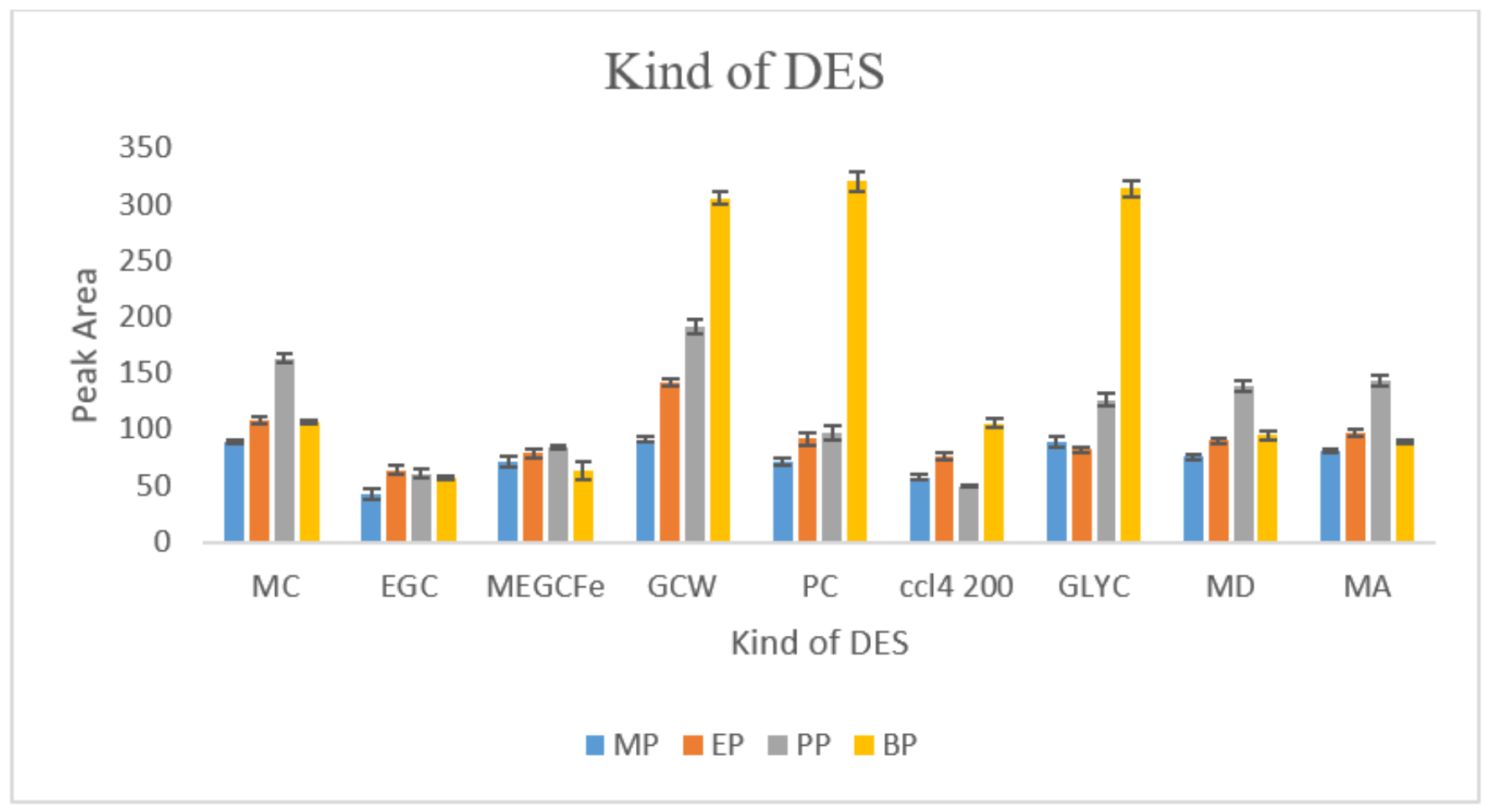

Figure 1

Kind of DES selection. 

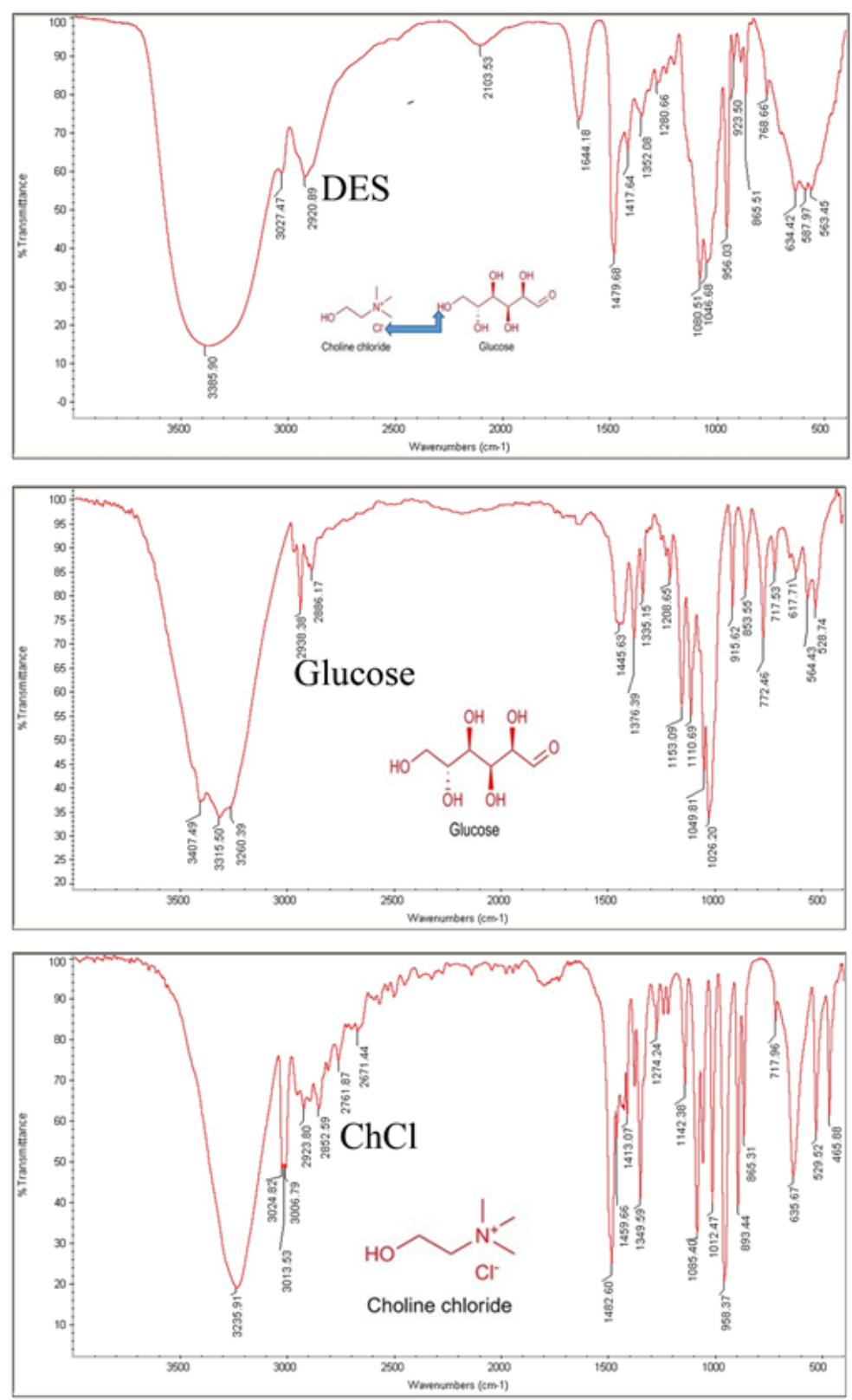

Figure 2

FT.IR spectra of DES, glucose, and cholin chlorid, ChCl.

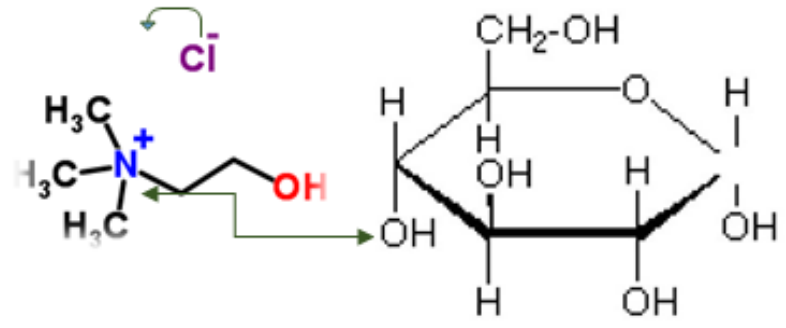

Figure 3

Hydrogen bonded between choline chloride and glucose. 


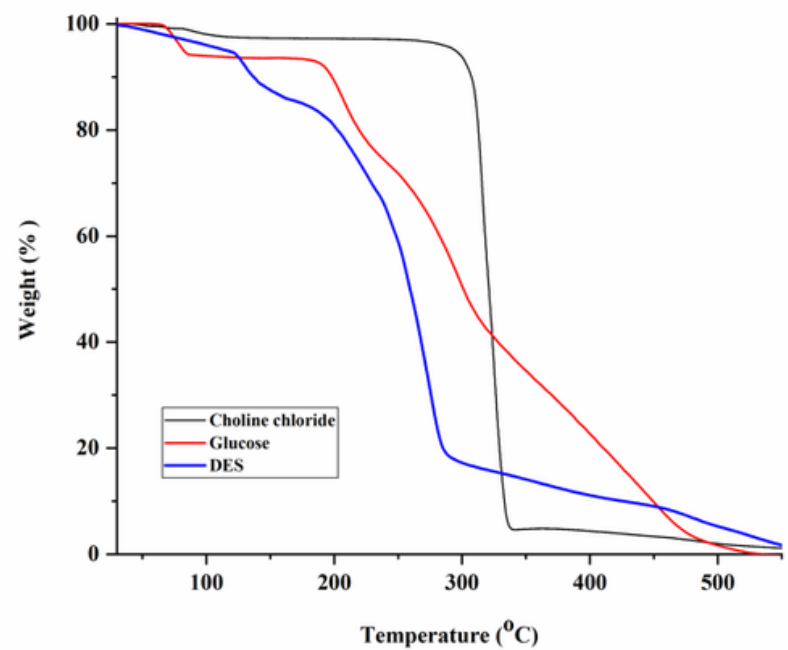

(a)

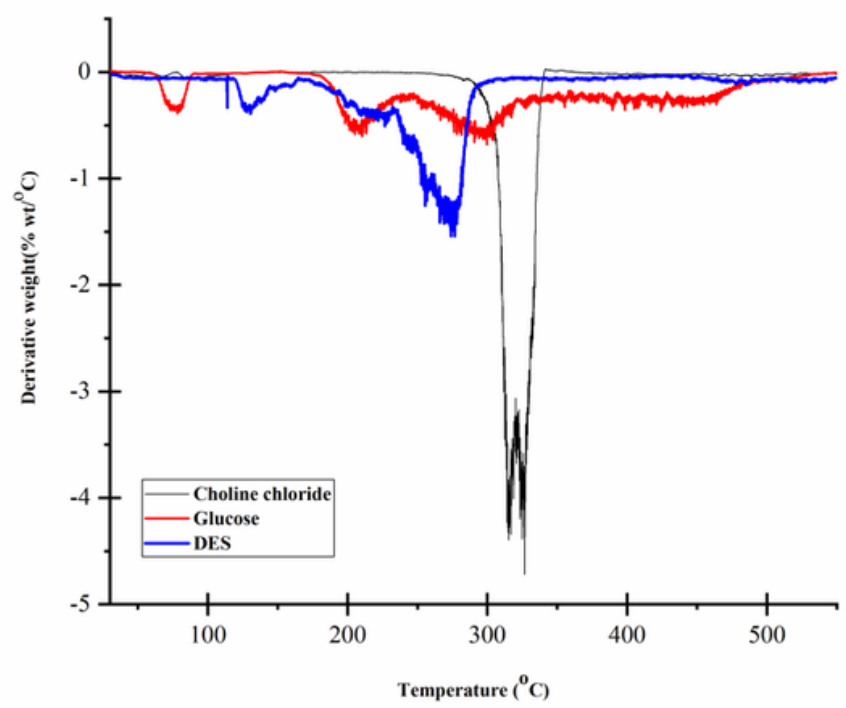

(b)

Figure 4

The variation of a) weight percentage (TGA) and $b$ ) the derivative of the weight percentage (DTG) curves of choline chloride, Glucose, DES as functions of temperature at $10 \mathrm{~K} / \mathrm{min}$.

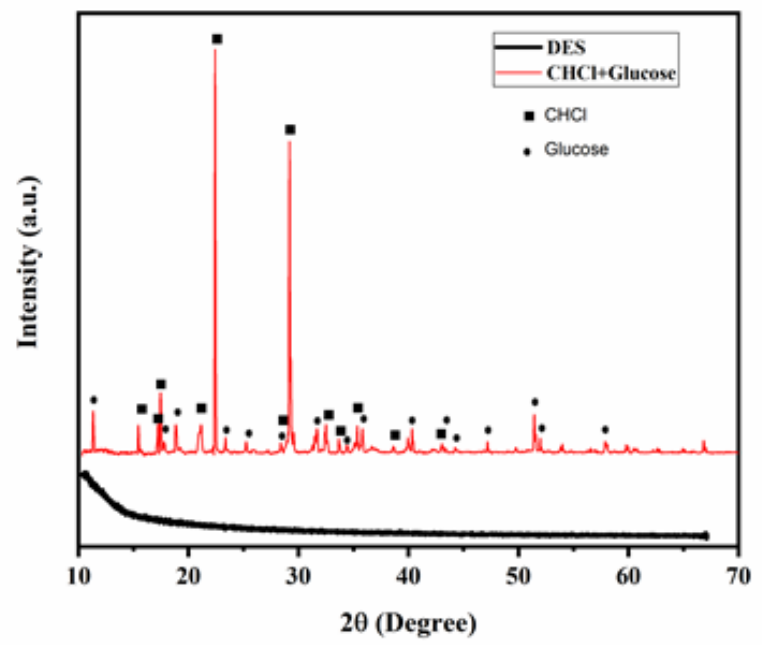

\section{Figure 5}

XRD graphs of DES and mixture of glucose and choline chloride. 


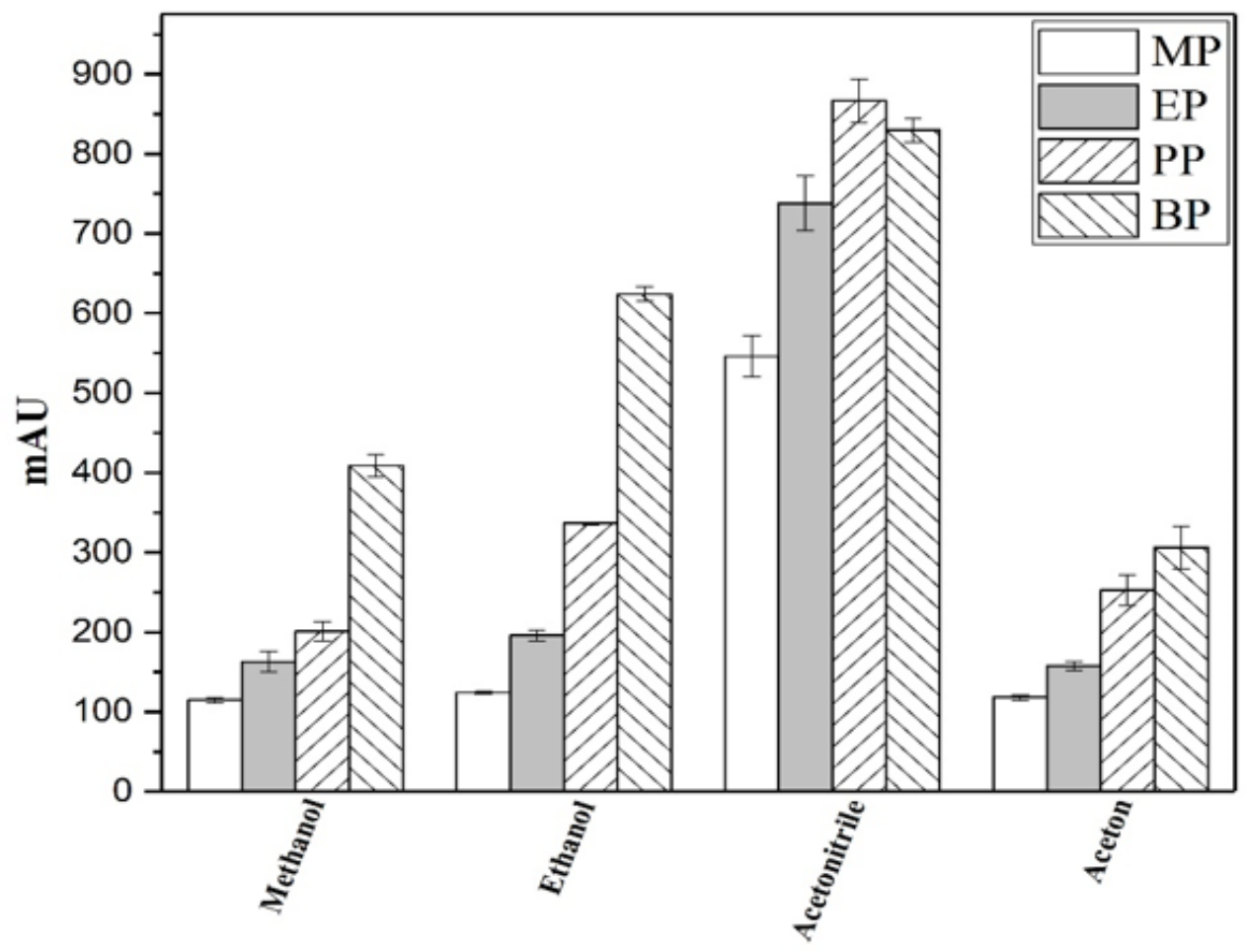

Figure 6

Kind of disperser solvent selection. 


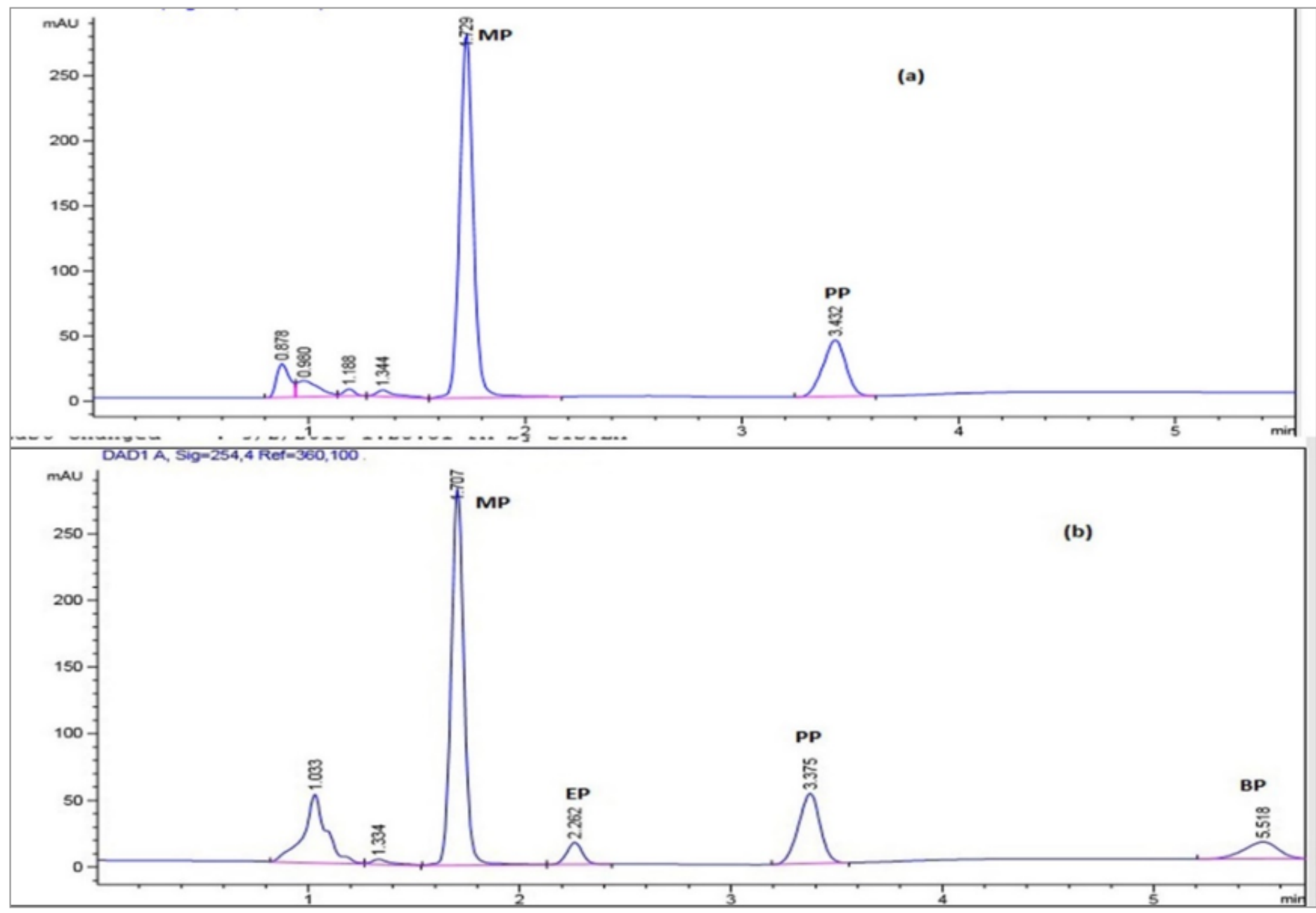

Figure 7

The sample chromatogram of extraction real sample (a) before and (b) after addition of standard solution

\section{Supplementary Files}

This is a list of supplementary files associated with this preprint. Click to download.

- NEWFIG.xIsx

- S2.docx 